\title{
Temperature Dependence of Density, Viscosity, Thermal Conductivity and Heat Capacity of Vegetable Oils for Their Use as Biofuel in Internal Combustion Engines
}

\author{
Augustin Sampawindé Zongo ${ }^{1 *}$, Gilles Vaïtilingom ${ }^{2}$, Tizane Daho' ${ }^{1}$ Christian Caillol ${ }^{3}$, \\ Jean-François Hoffmann ${ }^{4}$, Bruno Piriou ${ }^{2}$, Jeremy Valette ${ }^{2}$, Bila Gérard Segda ${ }^{1}$, Pascal Higelin ${ }^{3}$ \\ ${ }^{1}$ LPCE, Département de physique, Université Ouaga 1 Pr JKZ, Burkina Faso \\ ${ }^{2}$ Unité de recherche BioWooEB, CIRAD Montpellier, Bat 16, 73 rue JF Breton, Montpellier, France \\ ${ }^{3}$ Laboratoire PRISME, Université d'Orléans, 8 rue Léonard de Vinci, 45072 Orléans Cedex 2, France \\ ${ }^{4}$ Laboratoire PROMES-CNRS UPR-8521 Université de Perpignan Via Domitia, Rambla de laThermodynamique, Tecnosud, \\ Perpignan, France \\ Email: *zongosaugustin@yahoo.fr
}

How to cite this paper: Zongo, A.S., Vaïtilingom, G., Daho, T., Caillol, C., Hoffmann, J.-F., Piriou, B., Valette, J., Segda, B.G. and Higelin, P. (2019) Temperature Dependence of Density, Viscosity, Thermal Conductivity and Heat Capacity of Vegetable Oils for Their Use as Biofuel in Internal Combustion Engines. Advances in Chemical Engineering and Science, 9, 44-64.

https://doi.org/10.4236/aces.2019.91004

Received: December 8, 2018

Accepted: January 5, 2019

Published: January 8, 2019

Copyright $\odot 2019$ by author(s) and Scientific Research Publishing Inc. This work is licensed under the Creative Commons Attribution International License (CC BY 4.0).

http://creativecommons.org/licenses/by/4.0/

\begin{abstract}
This work gives tools to overcome the difficulty to determine experimentally physical properties for vegetable oils within the range of temperature typically observed during the injection phase in a diesel engine. Knowing vegetable oils' physical properties to these ranges of temperature is of fundamental importance when modeling their combustion in diesel engine. However, vegetable oils' experimental physical properties data are rare in the literature for temperature above $523 \mathrm{~K}$. This paper describes experimental measurements and estimation methods for density, dynamic viscosity, thermal conductivity and heat capacity of vegetable oils for this particular range of temperature. The methodology uses several correlative methods using group contribution approach for each property and compares experimental data with predicted one to select the more accurate model. This work has shown the rapeseed and jatropha oils' physical properties can be satisfactorily predicted as a function of temperature using group contribution approach.
\end{abstract}

\section{Keywords}

Rapeseed Oil, Jatropha Oil, Physical Properties, Group Contribution Method, Energy, Diesel Engine

\section{Introduction}

In the last three decades, several studies have shown the potential of pure vege- 
table oils as fuel in diesel engines and burners [1] [2] [3] [4] [5]. Their applications are numerous for developing countries: agriculture, irrigation, power and heat generation as well as drinking water supply. However, there are still problems related to their chemical and physical properties such as fatty acid composition, viscosity and volatility [6] [7] [8] [9] [10]. Their use may lead to the formation of carbon deposits under certain temperature conditions. These deposits can lead rapidly to engine mechanical failure. Studies have been conducted to determine the causes and possible solutions to the problems encountered in using vegetable oils as fuel in diesel engines [6] [11].

Many studies, mostly experimental, have described the mechanisms of evaporation and combustion of vegetable oils under different conditions of temperature and pressure [12] [13] and have determined their characteristics of evaporation. Attempts of models to calculate these characteristics are facing difficulties to correctly describe the transient phase. This phase of heating and dilatation takes place before the vaporization of vegetable oils droplets when they are introduced in diesel engines combustion chamber which minimum working temperature is above $450 \mathrm{~K}$. Taking account of this transient phase requires the knowledge of the physical properties such as density, viscosity, thermal conductivity and specific heat capacity, which data are rare in literature for temperature above $450 \mathrm{~K}$. Density, thermal conductivity, dynamic viscosity and heat capacity are useful for selecting fuels for internal combustion engines and have normative values in quality standards for commercial fuels used in compression ignition engines. Recent researches on the determination of the physical properties of alternative fuels have focused on biodiesel [14] [15] [16] [17] [18] or blends between diesel and other substances or mixtures [19] [20] [21] [22] [23]. Only a few studies have been interested in pure vegetable oils [24] [25] [26]. Indeed, determining vegetable oils physical properties is difficult because their composition varies from one oil to another. Furthermore, experimental measurements of these properties are difficult or impossible to perform over a certain level of temperature because of their decomposition [27]. Methods such Static Method and a Flow Method [28], Low Residence Time Flow Method [29] and the Pulse-Heating Method [30] are much more used to determine critical properties of pure compounds or unstable substances and mixtures.

Vegetable oils are mainly used for food purposes and therefore there are few data in literature on their physical properties up to $450 \mathrm{~K}$. This lack of data had to be overcome by experimental measurements and predictions for industrial use of vegetable oils. The main objective of this work is to determine experimentally vegetable oils density, viscosity, thermal conductivity and heat capacity up to $523 \mathrm{~K}$ and hence to predict the same physical properties for temperature above $523 \mathrm{~K}$ by means of predictive methods based on group contribution approach. At least two group contribution methods were tested for rapeseed and Jatropha oil density, viscosity, thermal conductivity and heat capacity which can be obtained experimentally or available in the literature. The physical properties 
above mentioned are evaluated as a function of temperature and the models which give very good agreement with literature or experimental data obtained in this work will be retained. The contribution of this work is to provide rapeseed and Jatropha experimental physical properties and predictive one by group contribution methodology that can be applied to others vegetable oils. Group contribution method has been used in recently works to estimate vegetable oils density [25] and viscosity [31], lower heating value [32], cetane number of biodiesel fuel [33], and fatty acid compounds viscosities [15], but few of them has determined properties above $450 \mathrm{~K}$. Jatropha curcas and rapeseed oils were chosen because they are respectively representative of southern and northern hemisphere first generation biofuels and also because of the availability of their physical properties data in the literature.

The critical properties such as critical temperature, critical pressure or critical volume are very important because they are involved in determining the physical properties mentioned above. Then, the critical properties and normal boiling point will be firstly determined by correlative method.

\section{Materials and Methods}

Experimental tests were carried out at CIRAD Biomass Energy Laboratory (UR BioWooEB) in Montpellier (France), with the collaboration of the "Laboratoire de Physique et de Chimie de l'Environnement" (Burkina Faso), and the PROMES-CNRS laboratory of Perpignan (France).

\subsection{Vegetable Oils}

Jatropha curcas oil was obtained from agricultural producers in Burkina Faso. Rapeseed oil is commercially available and was purchased in a refined standard state from a food reseller in France.

The physical and chemical characteristics in standard conditions of jatropha curcas and rapeseed oils used in this study were determined at BioWooEB. They are listed in Table 1 . The density values were obtained using a pycnometer following the NF EN ISO 12185 procedure. The dynamic viscosities were measured according to the NF EN ISO 3104. The flashpoints were obtained with a Pensky-Martens apparatus and using the NF EN ISO 2719 normative. We obtained the surface tension values by using the NF ISO 6295. Whereas lower heating values were measured in an Anton Paar Calorimeter type 6200 according to the NF EN 14918 method for solid biofuels, adapted and applied to liquids. The

Table 1. Physical characteristics of rapeseed oil and jatropha curcas oil.

\begin{tabular}{lcccccc}
\hline & $\begin{array}{c}\text { Density } \\
\left(\mathrm{kg} / \mathrm{m}^{3} \text { at }\right. \\
288 \mathrm{~K})\end{array}$ & $\begin{array}{c}\text { Kinematic } \\
\text { viscosity } \\
\left(\mathrm{mm}^{2} / \mathrm{s} \text { at } 313 \mathrm{~K}\right)\end{array}$ & $\begin{array}{c}\text { Flash } \\
\text { point }(\mathrm{K})\end{array}$ & $\begin{array}{c}\text { Surface } \\
\text { tension }(\mathrm{N} / \mathrm{m})\end{array}$ & $\begin{array}{c}\text { Low heating } \\
\text { value }(\mathrm{MJ} / \mathrm{kg})\end{array}$ & $\begin{array}{c}\text { Carbon } \\
\text { residue }(\%)\end{array}$ \\
\hline Rapeseed oil & 925 & 34.9 & 483 & 32.9 & 37.1 & 0.39 \\
Jatropha oil & 940 & 34 & 498 & - & 36.3 & - \\
\hline
\end{tabular}


carbon residue was measured by performing the NF EN ISO 10370 operation in a furnace of $773 \mathrm{~K}$. Some of these physical properties were determined at the IESPM on the request of the unit BioWooEB.

The fatty acid composition was determined by gas chromatography, using a Agilent $6890 \mathrm{GC}$ type with a FID detector and a CP-WAX 58CB column ( $25 \mathrm{~m} \times$ $0.32 \mathrm{~mm} \times 0.2 \mu \mathrm{m})$. The fatty acid composition of the oils is reported in Table 2 .

\subsection{Methods}

\subsubsection{Experimental}

In this section the experimental methods used to characterize the considered oils in the $298-523 \mathrm{~K}$ temperature range are described. The different methods or devices used in this work for the determination of density, dynamic viscosity, thermal conductivity and heat capacity of rapeseed and jatropha oils are listed in Table 3. These physical properties were carried out at the PROMES-CNRS laboratory in Perpignan.

The details of method $3 \omega$ can be obtained in the following literature [34].

\subsubsection{Correlative Methods}

A model that could predict pure vegetable oils physical properties based on the knowledge of their fatty acid composition would be useful in their direct use as fuel or in the optimization of biodiesel production processes or for the blending with others suitable products. On the basis of the fatty acid composition of the vegetable oils, the group contribution methods are known to be a powerful tool for predicting physical properties when experimental data are not available [15] [35]. Indeed, more than $95 \%$ of vegetable oil composition includes fatty acids. Furthermore, group contribution method is very effective to take into account of the contribution of glycerol that cannot be neglected for a more accurate estimate.

Table 2. Measured Fatty acids composition (peak area, \%) of rapeseed and jatropha oils.

\begin{tabular}{cccc}
\hline Fatty acids & Formula & Rapeseed oil & Jatropha oil \\
\hline Oleic $(\mathrm{C} 18: 1)$ & $\mathrm{C}_{18} \mathrm{H}_{34} \mathrm{O}_{2}$ & 60.78 & 41.64 \\
Linoleic $(\mathrm{C} 18: 2)$ & $\mathrm{C}_{18} \mathrm{H}_{32} \mathrm{O}_{2}$ & 19.22 & 32.53 \\
Linolenic $(\mathrm{C} 18: 3)$ & $\mathrm{C}_{18} \mathrm{H}_{30} \mathrm{O}_{2}$ & 8.92 & 0.00 \\
Palmitic $(\mathrm{C} 16: 0)$ & $\mathrm{C}_{16} \mathrm{H}_{32} \mathrm{O}_{2}$ & 4.78 & 16.00 \\
Stearic $(\mathrm{C} 18: 0)$ & $\mathrm{C}_{18} \mathrm{H}_{38} \mathrm{O}_{2}$ & 1.35 & 6.05 \\
Other minor fatty acids & - & 4.95 & 3.77
\end{tabular}

Table 3. Experimental devices or methods for rapeseed and jatropha oils physical properties determination.

\begin{tabular}{ccccc}
\hline $\begin{array}{c}\text { Physical } \\
\text { Properties }\end{array}$ & Density & $\begin{array}{c}\text { Dynamic } \\
\text { viscosity }\end{array}$ & $\begin{array}{c}\text { Thermal } \\
\text { conductivity }\end{array}$ & $\begin{array}{c}\text { Heat } \\
\text { capacity }\end{array}$ \\
\hline Device/Method & Pycnometer & $\begin{array}{c}\text { Rheometer } \\
\text { ARES-G2 }\end{array}$ & $3 \omega$ Method & DSC Setaram C80 \\
\hline
\end{tabular}


In this study, rapeseed and jatropha oils critical properties were estimated by using correlative methods that are based on group-contribution approach. Marrero and Gani (MG) method was used [36]. In fact, several studies [26] [36] [37] [38] show that this method performs better in terms of greater accuracy and wide applicability. Marrero and Gani method performs estimations at different levels: the primary level describes a wide variety of simple, monofunctional groups; the higher levels treat multifunctional structures and take into account the interactions among isomers functionalities.

For this method, each critical property is estimated by a function $f$ which depends, on the one hand on the different contributions of the functional groups at different levels as shown in the Equation (1) and on the other hand on the primary properties. The functions used for this work are listed in Table 4.

$$
f(X)=\sum_{i} N_{i} C_{i}+w \sum_{j} M_{j} D_{j}+z \sum_{k} O_{k} E_{k}
$$

$f(X)$ is a function of the property $X$ to be estimated, and $i, j$ and, $k$ refer to the first, second and third order groups defined in the group contribution method. $N_{i}$ and $M_{j}$ are the number of the $i$-th first order group, and the $j$-th second order group, respectively, present in the molecule, and $C$ and $D$ are the fitted contributions to the first and second order groups, respectively.

The approach used is based on the rapeseed and jatropha oils fatty acid composition: each fatty acid has been fragmented into several chemical groups and the contribution of each group is taken into account to get the contribution of the corresponding fatty acid. Then, the rapeseed or Jatropha oils critical properties can be estimated satisfactorily by taking into account their composition in fatty acids. For these different physical properties, at least two methods most suited for vegetable oils were considered and the best of them was retained.

\section{Density estimation}

There are several methods that can be used to estimate liquid density of pure or mixture compound [39]. However, the most important and accurate among them, and that is applicable to vegetable oils is Gunn Yamada's and Method of Ihmels et al. [38].

According to Gunn Yamada's estimation method, the pure compound liquid density is evaluated as follows Equations (2) to (6). The temperature range of this correlation extends from a reduced temperature of 0.20 to just below the critical temperature.

Table 4. Functions and constants for Marrero and Gani's group estimation method.

\begin{tabular}{ccc}
\hline Properties & Function $\mathbf{f}$ & Constants \\
\hline Boiling Point & $f(X)=\exp \left(T_{b} / T_{b o}\right)$ & $T_{b o}=222.543 \mathrm{~K}$ \\
Critical Temperature & $f(X)=\exp \left(T_{c} / T_{c o}\right)$ & $T_{c o}=231.239 \mathrm{~K}$ \\
Critical Pressure & $f(X)=\left(P_{c}-P_{c l}\right)^{0.5}-P_{c 2}$ & $P_{c 1}=5.9827 \mathrm{bar}, P_{c 2}=0.108998 \mathrm{bar}^{-0.5}$ \\
Critical volume & $f(X)=V_{c}-V_{c o}$ & $V_{c o}=7.95 \mathrm{~cm}^{3} / \mathrm{mol}$ \\
\hline
\end{tabular}




$$
\frac{1}{\rho}=V_{s c} V_{R}^{(o)}(1-\omega \Gamma)
$$

where

$$
\begin{gathered}
V_{s c}=\frac{\frac{1}{\rho_{r e f}}}{V_{R}^{(o)}\left(T_{r e f}\right)\left[1-\omega \Gamma\left(T_{r e f}\right)\right]} \\
\text { and } \Gamma=0.29607-0.09045 T_{R}-0.04843 T_{R}^{2}
\end{gathered}
$$

and $\omega$ is the acentric factor and is calculated using Equation (5)

$$
\frac{P_{c} V_{c}}{R T_{C}}=0.291-0.080 \omega
$$

where $P_{c}, T_{c}$ and $V_{c}$ are the critical pressure, temperature and volume, respectively. $T_{\text {ref }}$ is a reference temperature, generally ambient temperature, $\rho_{\text {ref }}$ is the density at the reference temperature.

$$
V_{R}^{(O)}=0.33593-0.33593 T_{R}+1.51941 T_{R}^{2}-2.02512 T_{R}^{3}+1.11422 T_{R}^{4}
$$

for temperature ranges corresponding to $0.2 \leq T_{R} \leq 0.8$ where $T_{R}$ is the reduced temperature with $T_{R}=\frac{T}{T_{C}}$. In this study, reference data are these obtained experimentally at $298 \mathrm{~K}$ from this study.

Ihmels and Gmehling [38] extended and revised the group contribution method GCVOL developed by Elbro et al. for the prediction of liquid density. According to this method, the density of vegetable oils can be estimated by the Equation (7) below:

$$
\rho=\frac{M_{w}}{V}=\frac{M_{w}}{\sum n_{i} \Delta v_{i}}
$$

where $M_{W}$ is the molecular weight and $V$ the molar volume. The molar volume is obtained by summing up all the group volume contributions $\Delta v_{i}$ with $n_{i}$ the number of group $i$ appearing in the compound, while $\Delta v_{i}$ is expressed as a polynomial function of absolute temperature:

$$
\Delta v_{i}=A_{i}+B_{i} T+C_{i} T^{2}
$$

where the units are $\mathrm{K}$ for temperature and $\mathrm{cm}^{3} \cdot \mathrm{mol}^{-1}$ for $\Delta v_{i^{\circ}}$ Group functional and there parameters $A_{\mathrm{i}}, B_{i}$ and $C_{i}$ can be seen in this literature [39].

The molecular weight of vegetable oils can be estimated using Equation (9):

$$
M_{w}=3 \sum x_{i} M_{w i}+38.0488 \quad[40]
$$

\section{Dynamic viscosity estimation}

The most important methods used for dynamic viscosity estimation of pure compounds are based on group contribution models proposed by Jöback-Lydersen's [39] and by Morris [41].

Jöback-Lydersen's method used a simple correlation given by Equation (10):

$$
\mu=M_{w} \cdot \exp \left[\frac{\sum \Delta \mu_{a}-597.82}{T}+\sum \Delta \mu_{b}-4.294\right][42]
$$


where $\Delta \mu_{a}$ and $\Delta \mu_{b}$ are Jöback groups' contributions which are given and $T$ is the temperature. No temperature limitations are specified for this method except for the fact that the temperature must be less than the critical.

For Morris's Method, the dynamic viscosity $\mu_{L}$ can be estimated using Equation (11) to Equation (12).

$$
\begin{array}{r}
\log _{10} \frac{\mu_{L}}{\mu^{+}}=J\left(\frac{1}{T_{R}}-1\right) \\
\text { where } J=\left(0.577+\sum \Delta \mu_{M}\right)^{1 / 2}
\end{array}
$$

$\Delta \mu_{M}$ represents the group contributions factors which are given and $\mu^{+}$is compound class group contribution. This method is limited to temperatures less than 0.8 times the critical temperature.

\section{Thermal conductivity estimation}

For thermal conductivity estimation of rapeseed and jatropha oils respectively, two methods based on group contribution method proposed by Sastri, and Sato-Riedel [39] were selected. Sastri method gives the thermal conductivity $\lambda_{L}$ by Equation (13) below:

$$
\lambda_{L}=\lambda_{b} a^{m}
$$

where $m$ is given by Equation (14)

$$
m=1-\left(\frac{1-T_{R}}{1-T_{b r}}\right)^{n}
$$

and $\lambda_{b}$ is calculated using the group contribution method Equation (15):

$$
\lambda_{b}=\sum \Delta \lambda_{b}+\sum \Delta \lambda_{\text {corr }}
$$

$\Delta \lambda_{b}$ is the group contribution value of the different groups and $\Delta \lambda_{\text {corr }}$ is a correction factor which may be required for some compounds. " $a$ " and " $n$ " are constants. Excepted for alcohols and phenols (where $a=0.856$ and $n=1.23$ ) the values for these constants are respectively 0.160 and 0.20 for most compounds [6], $T_{b r}$ is the ratio of the boiling temperature and the critical temperature.

Sato-Riedel method is based on the equation of Sato-Riedel Equation (16) as follow:

$$
\lambda=\frac{1.1053 *\left(3+20\left(1-T_{R}\right)^{2 / 3}\right)}{\left(3+20\left(1-T_{b r}\right)^{2 / 3}\right) * M_{w}^{1 / 2}}
$$

The upper temperature limit for Sato-Riedel method is the critical point and thermal conductivity will not be calculated at temperatures above this.

\section{Heat capacity at constant pressure $\left(C_{p}\right)$ estimation}

Two methods were selected to estimate the heat capacity at constant pressure. The most accurate method was chose by comparing the values of the estimated properties with experimental values of this study. Zong et al. [43] developed an approach based on chemical constituent fragments to estimate the thermo physical properties. The heat capacity $C_{p}^{l}$ can be estimated by Equation (17) ac- 
cording to this approach.

$$
C_{P}^{l}=\sum_{A} N_{\text {frag }, A} C_{P, A}^{l}(T)
$$

where $C_{P, A}^{l}=A_{1, A}+A_{2, A} T$ (18), $A_{1, A}$ and $A_{2, A}$ are parameters of temperature dependent correlation for fragment $A$ and $T$ is the temperature (K), and $N_{\text {frag, } A}$ is the number of fragments $A$ in the component. The detail of Zong et al. method and the others parameters can be found in the following references [38] [43].

Ceriani et al. [44] applied group contribution method to predict heat capacity for fatty compounds and oils. The equation used is given by Equation (18)

$$
C_{P i}^{l}=\sum_{k} N_{k} \cdot\left(A_{k}+B_{k} T\right)
$$

where $N_{k}$ is the number of group $k$ in the molecule and $A_{k} B_{k}$ are parameters obtained from the regression. The detail of Ceriani et al. [38] [44] method and the others parameters can be found in the following literature [39].

No temperature limit was found for Ceriani et al. and Zong et al. methods.

\section{Results and Discussion}

For all the physical properties, the Average Relative Deviation (ARD) which formula given by Equation (19) is used to evaluate the accuracy of the different studied methods and for the validation of the estimated values.

$$
\operatorname{ARD}(\%)=\frac{1}{N} \sum_{1}^{N} 100 *\left|\operatorname{Exp}_{V}-\operatorname{Est}_{V}\right| / \operatorname{Exp}_{V}
$$

where $N$ is the number of data points, $\operatorname{Exp}_{V}$ is experimental value, $E s t_{V}$ is estimated value.

\subsection{Results for Critical Properties and Normal Boiling Point}

Table 5 shows the results of critical properties and normal boiling point predicted by the MG method for rapeseed and Jatropha oils.

To test the reliability of MG method, the estimated values of this study have been compared with literature data. However, there are literature data for only canola oil which is another variety of rapeseed oil and then is used for comparison.

Table 5. Rapeseed and Jatropha oil estimated critical properties and normal boiling point by MG method.

\begin{tabular}{cccccc}
\hline \multicolumn{2}{c}{ Physical Properties } & $T_{B}(\mathrm{~K})$ & $T_{C}(\mathrm{~K})$ & $P_{C}(\mathrm{bar})$ & $V_{C}\left(\mathrm{~cm}^{3} / \mathrm{mol}\right)$ \\
\hline \multirow{3}{*}{ Rapeseed oil } & This study* & 638.01 & 811.02 & 14.17 & 1.05 \\
& Literature [36] [45] & 626.10 & 818.95 & 12.85 & 1.04 \\
& ARD (\%) & 1.90 & 0.96 & 10.27 & 1.25 \\
& This study & 634.51 & 838.39 & 14.35 & 1.03 \\
Jatropha oil & Literature [36] & 623.60 & 837.47 & 13.02 & 1.03 \\
& ARD (\%) & 1.75 & 0.10 & 10.21 & 0.68 \\
\hline
\end{tabular}

*values of parameters calculated by the authors using the Marrero-Gani's method. 
As shown in Table 5, the relative deviation between literature data and estimated values for rapeseed and jatropha oils are low for $T_{B}, T_{C}$ and $V_{C}$ confirming the reliability of MG method. Large deviations were only observed for critical pressure in both cases. Poling et al. [39] have already noted that for the estimation of the critical pressure, the largest errors are found for the heavier molecules, consequently the estimations may be too high or too low with no obvious pattern for errors under these conditions. This could therefore explain the high ARD for vegetable oils, since they are formed of triglycerides which are large molecules.

\subsection{Experimental Results of Rapeseed and Jatropha Oils Physical Properties}

The experimental data of this work for physical properties of rapeseed and Jatropha oils, for the temperature range 298 to $523 \mathrm{~K}$, using the different methods and devices above mentioned are given in Table 6.

Figure 1 and Figure 2 show curves evolution of experimental density, heat capacity, thermal conductivity and dynamic viscosity. Figures indicate that all physical properties of the two oils above mentioned decrease as the temperature increases except the heat capacity which increases along with temperature. For the viscosity, the effect of temperature is related to the decrease of intermolecular forces, making easier the flow and therefore the reduction of viscosity [46]. In

Table 6. Experimental values for secondary physical properties of rapeseed and jatropha oils obtained in this work.

\begin{tabular}{|c|c|c|c|c|c|c|c|c|}
\hline $\begin{array}{l}\text { Physical } \\
\text { property }\end{array}$ & \multicolumn{2}{|c|}{$\begin{array}{l}\text { Density } \\
\left(\mathrm{kg} / \mathrm{m}^{3}\right)\end{array}$} & \multicolumn{2}{|c|}{$\begin{array}{l}\text { Dynamic viscosity } \\
(\mathrm{mPa} \cdot \mathrm{s})\end{array}$} & \multicolumn{2}{|c|}{$\begin{array}{c}\text { Thermal } \\
\text { conductivity }(\mathrm{W} / \mathrm{m} . \mathrm{K})\end{array}$} & \multicolumn{2}{|c|}{$\begin{array}{l}\text { Heat capacity } \\
\quad(\mathrm{J} / \mathrm{g} . \mathrm{K})\end{array}$} \\
\hline $\begin{array}{l}\text { Mesasurement } \\
\text { error }\end{array}$ & \multicolumn{2}{|c|}{0.051} & \multicolumn{2}{|c|}{0.10} & \multicolumn{2}{|c|}{0.012} & \multicolumn{2}{|c|}{0.037} \\
\hline $\begin{array}{c}\text { Temperature } \\
(\mathrm{K})\end{array}$ & $\begin{array}{l}\text { rapeseed } \\
\text { oil }\end{array}$ & $\begin{array}{c}\text { Jatropha } \\
\text { oil }\end{array}$ & $\begin{array}{l}\text { rapeseed } \\
\text { oil }\end{array}$ & $\begin{array}{c}\text { Jatropha } \\
\text { oil }\end{array}$ & rapeseed & ropha oil & $\begin{array}{c}\text { rapeseed } \\
\text { oil }\end{array}$ & $\begin{array}{c}\text { Jatropha } \\
\text { oil }\end{array}$ \\
\hline 298 & 911.462 & 914.99 & 134.868 & 88.839 & 0.1654 & 0.1681 & 2.0294 & 2.0373 \\
\hline 303 & 908.117 & 911.294 & 97.7675 & 63.5536 & 0.1648 & 0.1670 & 2.0313 & 2.0642 \\
\hline 323 & 894.735 & 896.51 & 39.6956 & 24.8646 & 0.1617 & 0.1630 & 2.0739 & 2.1903 \\
\hline 343 & 881.353 & 881.726 & 21.9229 & 13.4007 & 0.1587 & 0.1591 & 2.1512 & 2.3228 \\
\hline 363 & 867.971 & 866.942 & 14.0706 & 8.4454 & 0.1559 & 0.1555 & 2.2398 & 2.4377 \\
\hline 383 & 854.589 & 852.158 & 9.8750 & 5.8414 & 0.1533 & 0.1521 & 2.3227 & 2.5197 \\
\hline 403 & 841.207 & 837.374 & 7.3539 & 4.2976 & 0.1508 & 0.1489 & 2.3891 & 2.5622 \\
\hline 423 & 827.825 & 822.59 & 5.7129 & 3.3041 & 0.1485 & 0.1460 & 2.4345 & 2.5674 \\
\hline 443 & 814.443 & 807.806 & 4.5808 & 2.6254 & 0.1464 & 0.1433 & 2.4605 & 2.5458 \\
\hline 463 & 801.061 & 793.022 & 3.7645 & 2.1402 & 0.1444 & 0.1408 & 2.4750 & 2.5171 \\
\hline 483 & 787.679 & 778.238 & 3.1551 & 1.7807 & 0.1426 & 0.1385 & 2.4920 & 2.5094 \\
\hline 503 & 774.297 & 763.454 & 2.6872 & 1.5067 & 0.1409 & 0.1364 & 2.5319 & 2.5595 \\
\hline 523 & 760.915 & 748.67 & 2.3195 & 1.2927 & 0.1394 & 0.1346 & 2.6212 & 2.7129 \\
\hline
\end{tabular}




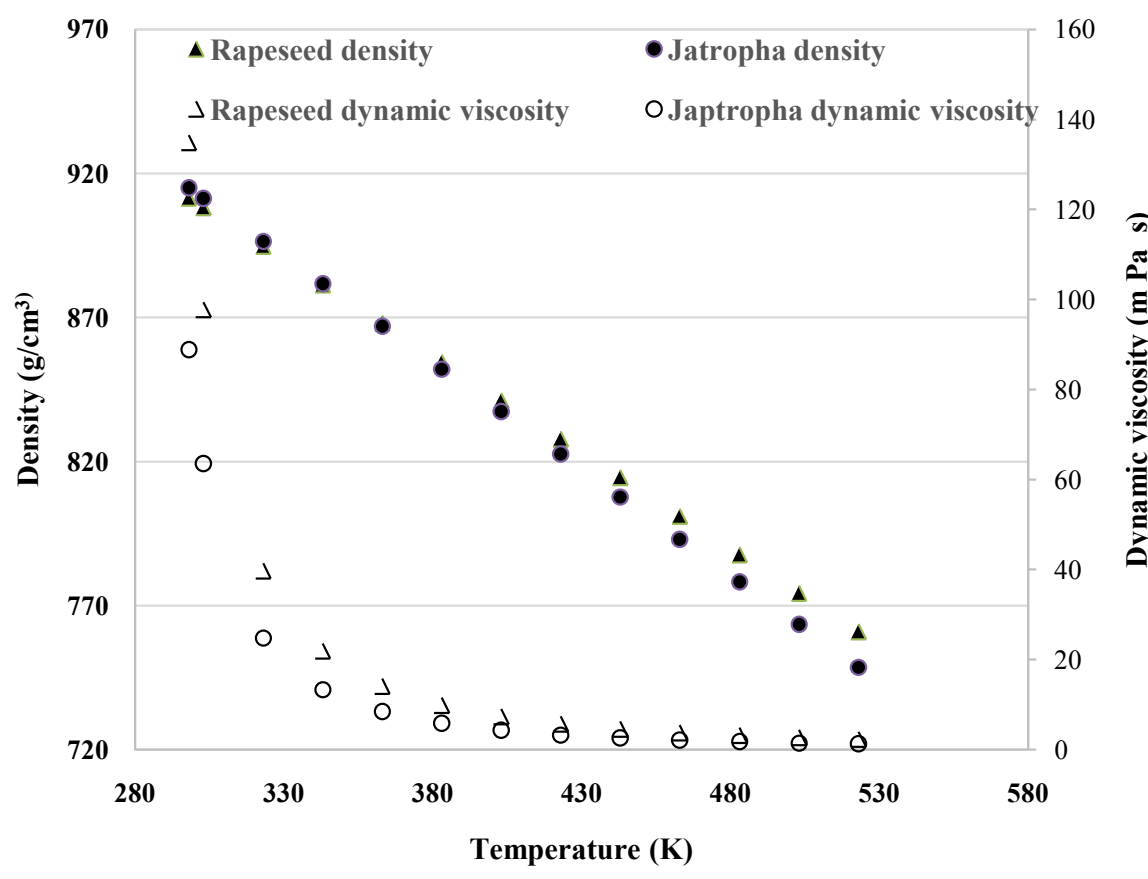

Figure 1. Experimental density and dynamic viscosity curves evolution of rapeseed and Jatropha versus temperature.

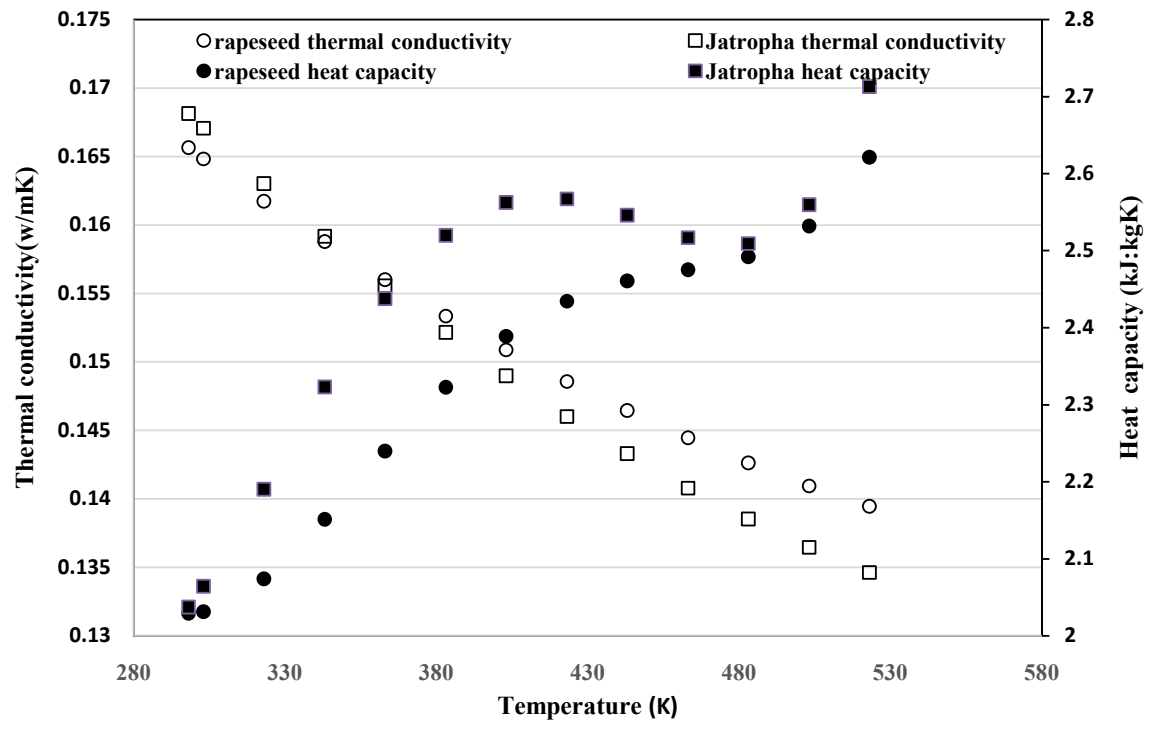

Figure 2. Experimental thermal conductivity and heat capacity curves evolution of rapeseed and Jatropha versus temperature.

the case of density, when the temperature increases, the molecules disperse and the fluid expands in occupying a larger space. As the mass of the fluid remains identical, this expansion causes a decrease in the density. However, the specific heat of the two oils increases along with increasing temperature. This trend confirms the experimental results obtained by Morad et al. [40] with DSC method. They also found that this increase in heat capacity with temperature is related to the mobility of the molecules depending on the temperature. 


\subsection{Estimated Physical Properties for Rapeseed and Jatropha Oils}

\subsubsection{Density}

Figure 3 and Figure 4 show respectively the estimated and experimental density values for rapeseed and Jatropha oils as a function of temperature. In both cases, the estimated and experimental data show the same trend with temperature: density decreases when temperature increases. In particular when temperature increases the Gunn Yamada density curve gets closer to the experimental one while the Ihmels et al.'s density curve is closer to the experimental one at low temperatures and deviates more and more as the temperature increases. In addition, low deviations between experimental values and predicted one were found with the two methods as shown in Table 7 showing the goodness

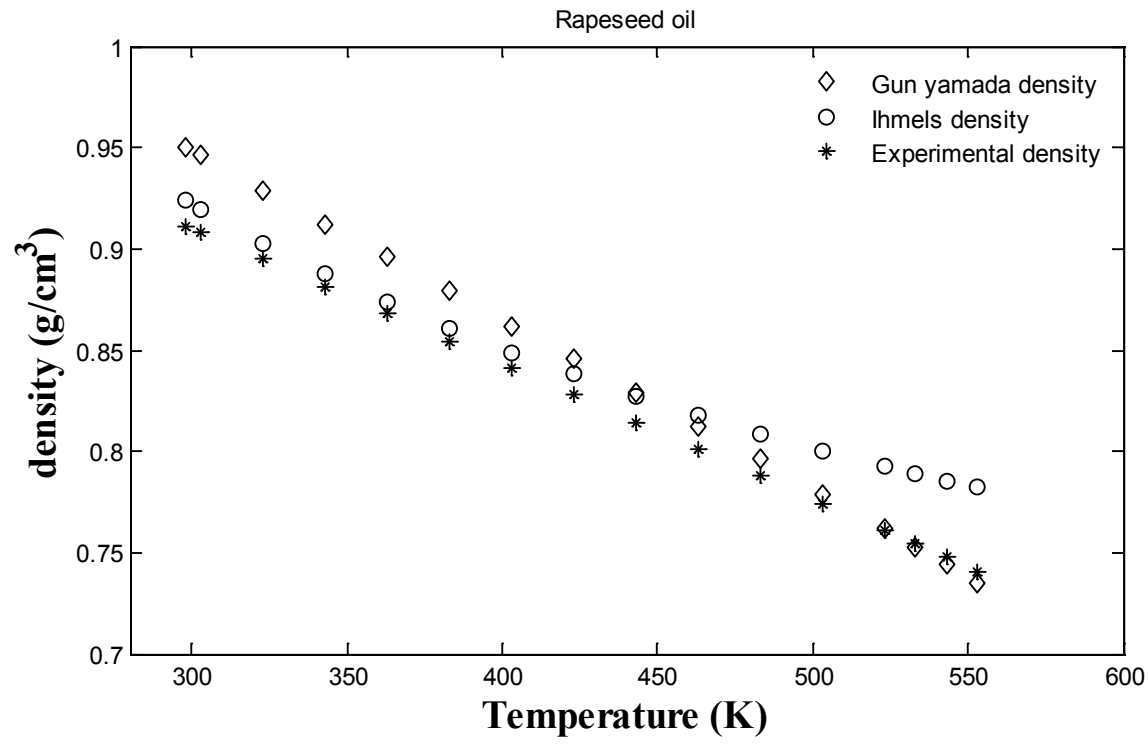

Figure 3. Experimental and estimated density of rapeseed oil.

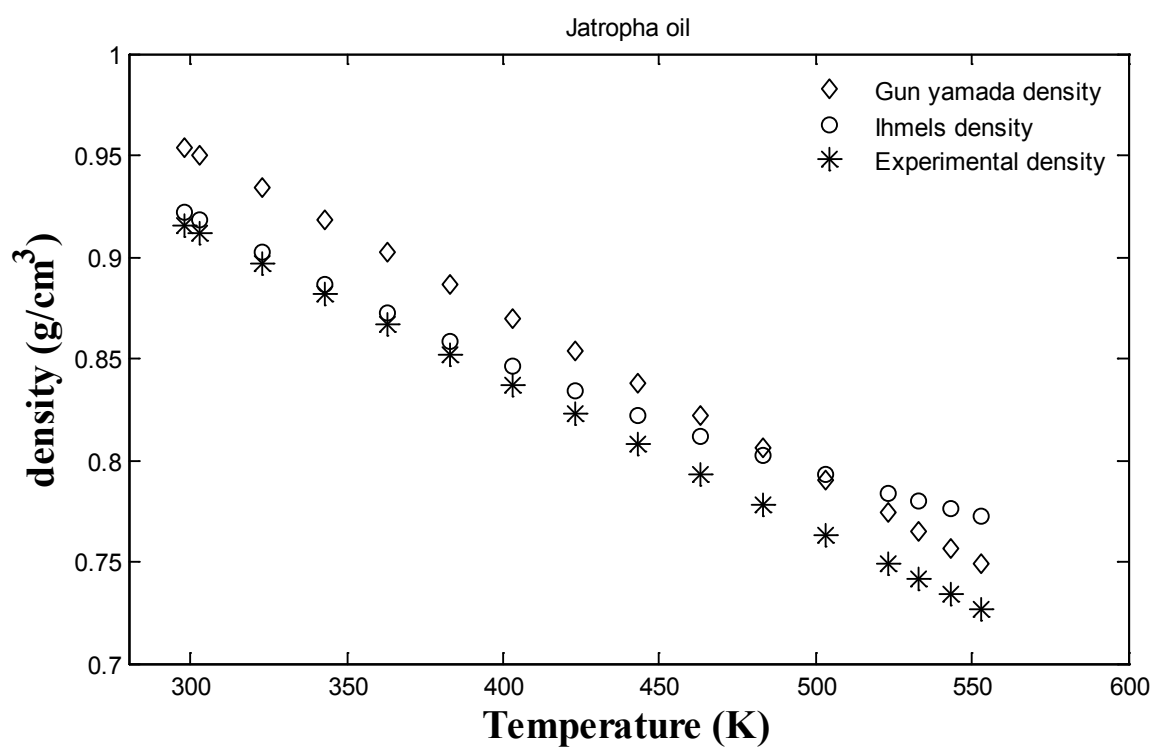

Figure 4. Experimental and estimated density of jatropha oil. 
Table 7. ARD values for the different methods used.

\begin{tabular}{ccccc}
\hline \multirow{2}{*}{ Property } & \multirow{2}{*}{ Estimation method } & \multicolumn{2}{c}{ ARD (\%) } & data points \\
\cline { 3 - 5 } & & Rapeseed oil & Jatropha oil \\
\hline \multirow{2}{*}{ Density } & Gunn Yamada & 2.05 & 3.73 & 16 \\
& Ihmels et al. Gmehling & 2.30 & 2.45 & 16 \\
\multirow{2}{*}{ Dynamic Viscosity } & Jöback-Lydersen & 28.39 & 20.42 & 14 \\
& Morris & 32.42 & 58.93 & 14 \\
Thermal conductivity & Sastri & 5.05 & 1.29 & 14 \\
& Sato-Riedel & 34.30 & 39.32 & 14 \\
Heat Capacity & Zong et al. & 6.18 & 7.75 & 14 \\
& Ceriani et al. & 19.03 & 12.18 & 14 \\
\hline
\end{tabular}

of the two correlatives methods. However, in view of the purpose of this work, Gunn Yamada correlative method is recommended for extrapolation of density at high temperatures typically observed during the injection phase in diesel engine. Ihmels et al's method is then recommended for determined edible vegetable oils properties for food purposes.

\subsubsection{Dynamic Viscosity}

The accuracy of the experimental measurements by considering the imperfections of the geometry and the precision of the rheometer was estimated to be in the order of $10 \%$. Two estimation methods have been discussed. In Figure 5 and Figure 6, calculated dynamic viscosities are compared with experimental values for rapeseed and jatropha oils.

For temperatures lower than $350 \mathrm{~K}$, large errors result, as illustrated on both figures for the two methods. This is due to the fact that Jöback-Lyderson and Morris viscosity correlations [39] [41] don't assume that $\ln$ is a linear function of reciprocal temperature. Because generally for a temperature range from the freezing point to the normal boiling temperature, when the natural logarithm of dynamic viscosity is assume to be a linear reciprocal absolute temperature, good approximation is found.

Therefore, for low temperatures, deviations can be observed. In the same range of temperature, experimental values of viscosity are higher than estimated ones obtained by Jöback-Lyderson and Morris. The two methods give similar accuracies and tend to underestimate vegetable oil dynamic viscosity but the method of Jöback-Lyderson yields the smallest errors.

When the temperature increases from $350 \mathrm{~K}$, relative deviations become smaller and the experimental and estimated curves tend to overlap, especially with the method of Jöback-Lyderson. For higher accuracy, the Jöback-Lyderson method can be selected. In the literature [39] there are generally distinct methods of correlations or viscosities at low temperatures and for high temperature. However, the problem lies in the impossibility of combining the two estimated viscosities. 


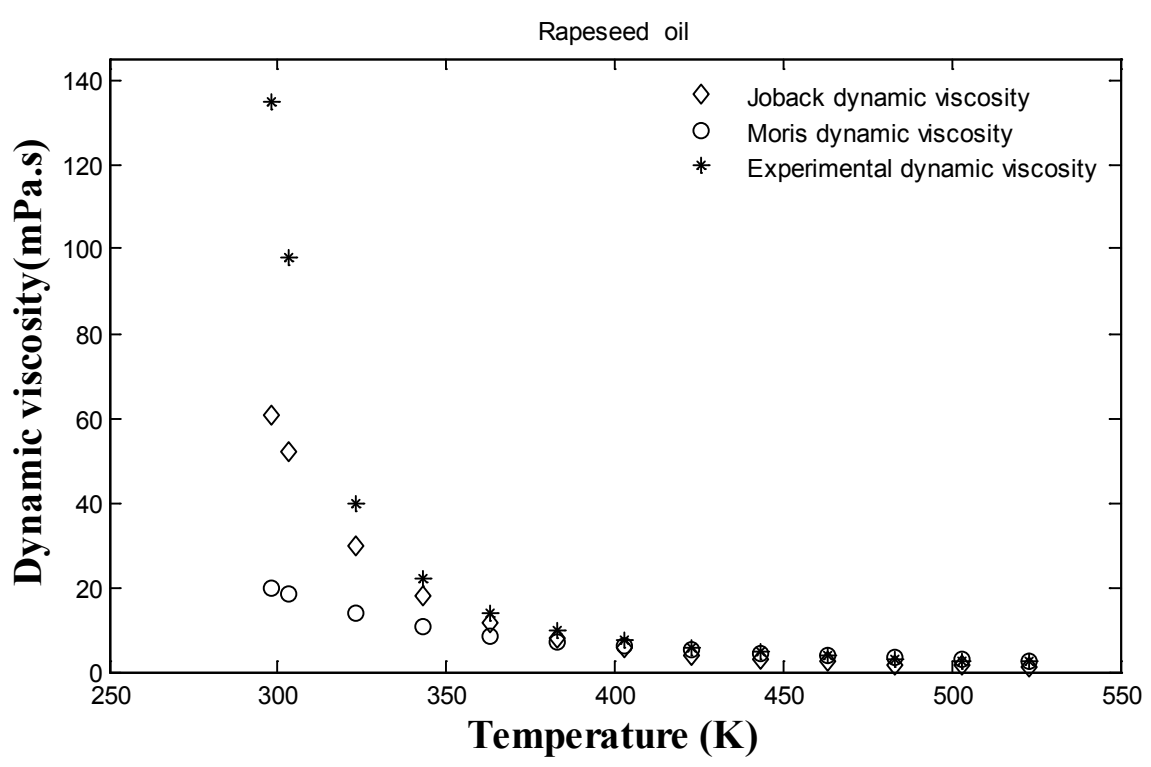

Figure 5. Experimental and estimated dynamic viscosity of rapeseed oil.

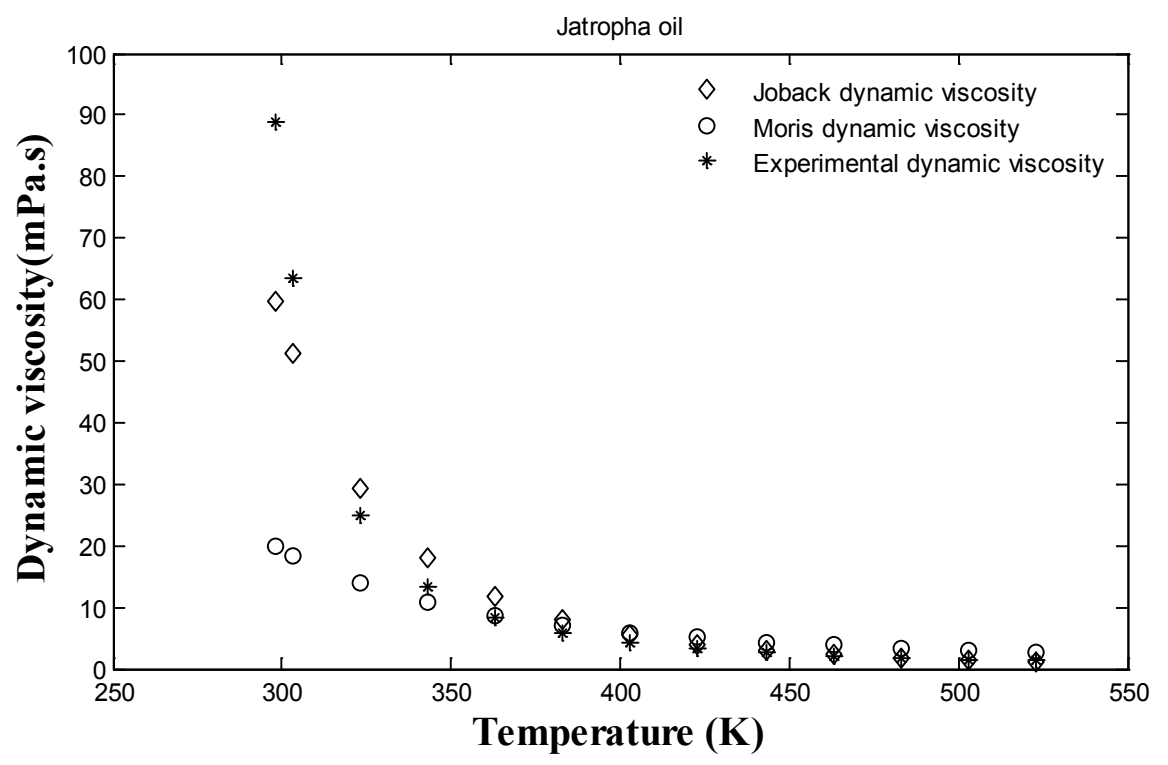

Figure 6. Experimental and estimated dynamic viscosity of jatropha oil.

\subsubsection{Thermal Conductivity}

Table 8 shows the reproducibility error of the device for measuring the thermal conductivity of vegetable oils. The measuring device was found to lead to a reproducibility error of about $1.2 \%$.

Two estimation methods have been discussed: Sastri and Riedel methods [39]. In Figure 7 and Figure 8, calculated thermal conductivity is compared with experimental values for rapeseed and jatropha oils. As expected, in both figures, the results show that the thermal conductivity decreases when the temperature increases. However, the difference between the thermal conductivity obtained by the two estimative methods is very large. The average relative deviation between the estimated thermal conductivity and the experimental values is about $5 \%$ for 
Table 8. Reproducibility errors for measuring the thermal conductivity of vegetable oils.

\begin{tabular}{cccc}
\hline Method & Error $(\%)$ & Oil & Reference \\
\hline Photoacoustic & 2 & Sunflower & Soybean \\
Thermal analyser & 3 & Sunflower $\left(21^{\circ} \mathrm{C}\right)$ & Sunflower $\left(68.7^{\circ} \mathrm{C}\right)$ \\
& 1,8 & Soybean $\left(21^{\circ} \mathrm{C}\right)$ & \\
\hline
\end{tabular}

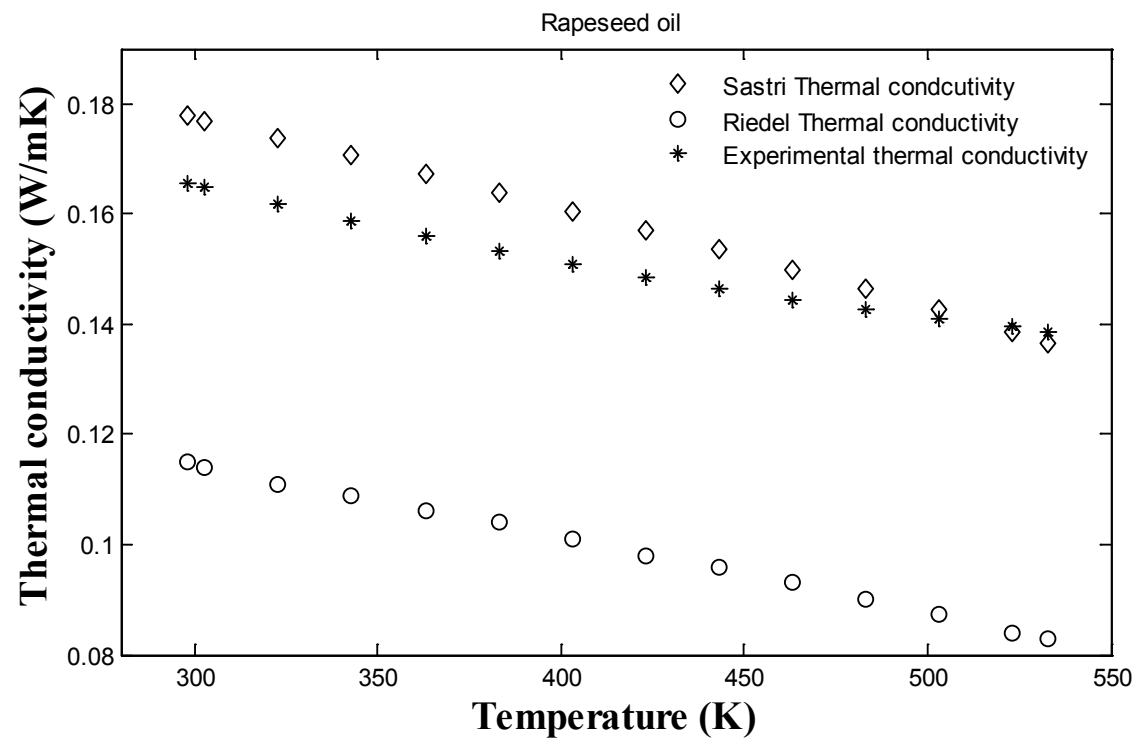

Figure 7. Experimental and estimated thermal conductivity of rapeseed oil.

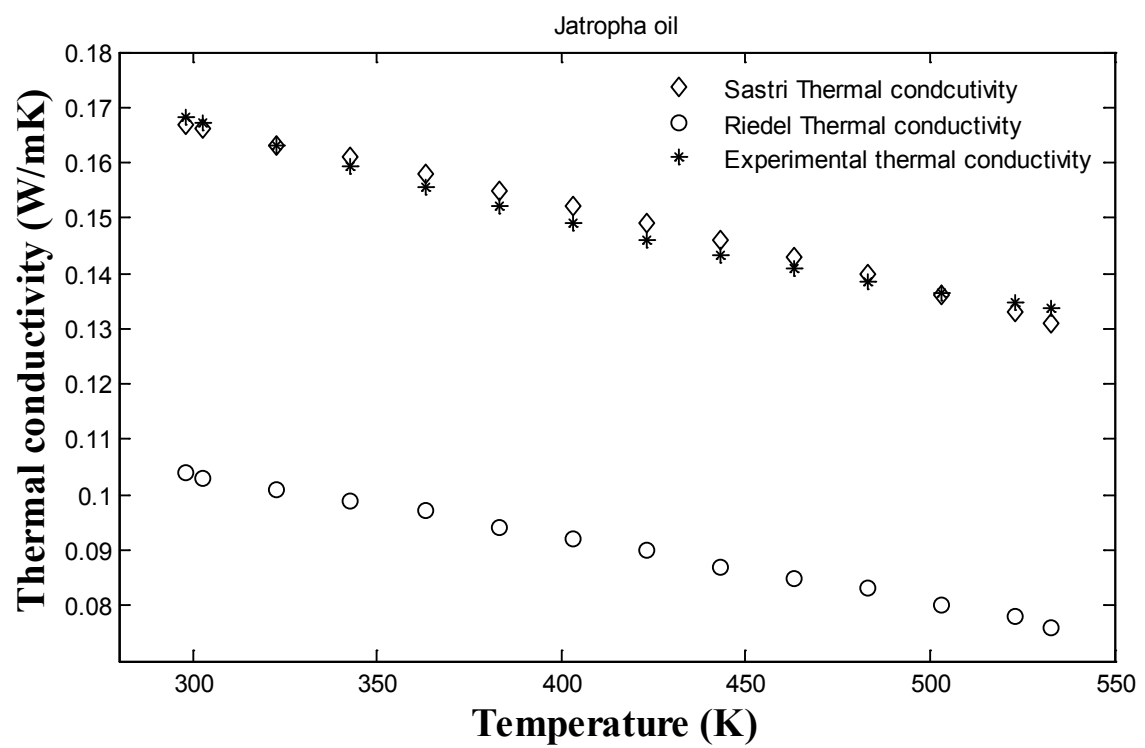

Figure 8. Experimental and estimated thermal conductivity of jatropha oil.

Sastri method. Riedel method overestimates the rapeseed and jatropha oils thermal conductivity. Then, Sastri method gives good agreement between pre- 
dicted thermal conductivity and experimental thermal conductivity data in the studied temperature range. The higher agreement of Sastri method with experimental values is probably due to the fact that this correlative method involves the contribution of functional groups as well as correction factors, whereas the Riedel method involves only a reference value and a reduced temperature.

\subsubsection{Heat Capacity at Constant Pressure $\left(C_{p}\right)$}

Two methods for estimating liquid heat capacities were considered. Figure 9 and Figure 10 show comparison of estimated values and experimental data of heat capacity for rapeseed and jatropha oils. For all the considered cases, the heat capacity increases along with the temperature. The figures show that Zong et al.

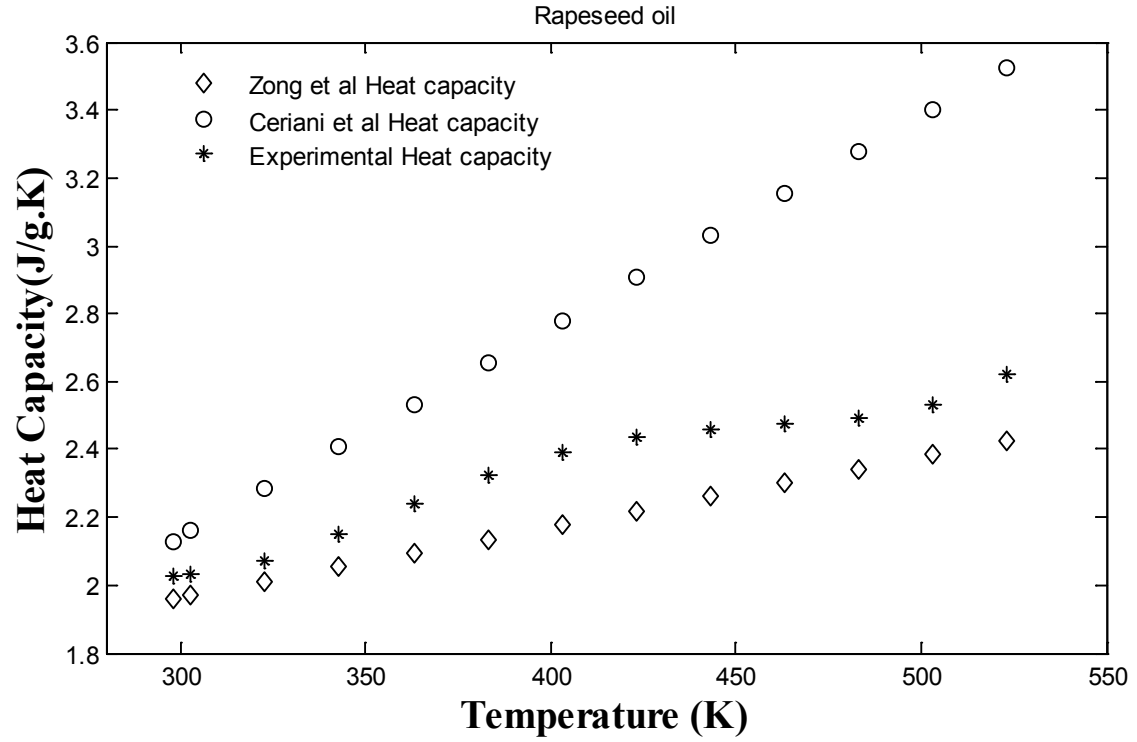

Figure 9. Experimental and estimated thermal heat capacity of rapeseed oil.

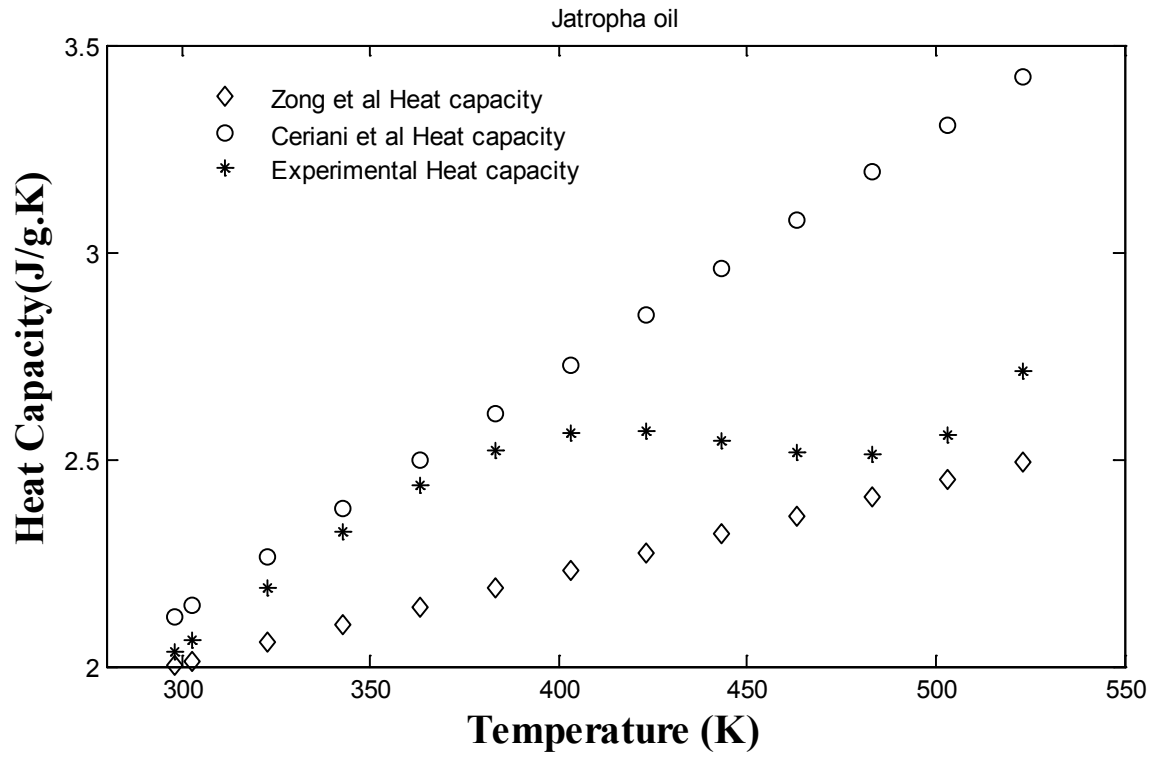

Figure 10. Experimental and estimated thermal heat capacity of jatropha oil. 
[43] method give large negative deviation, while Ceriani et al. method has small positive deviation [44]. Ceriani's method gives very low errors especially for relatively low temperatures $(<400 \mathrm{~K})$. But in the considered temperature range, Zong et al. method shows satisfactory agreement with experimental data for both vegetable oils. This can be seen in Table 7 for ARD values. Zong's method is based on a fragmentation approach of the molecule which is likely to occur at higher temperature whereas Cerani's method is based on the functional groups. This shows that for low temperatures, the functional group approach is better than that of the fragmentation approach. But both of these methods yield better results which show that although the vegetable oils are formed of triglycerides which are themselves formed of fatty acids, their physical properties can be determined successfully by fragmentation or group contribution approach.

In addition, while the curve of the three methods evolves linearly, the experimental one varies first linearly and then changes the slope from $450 \mathrm{~K}$. This clearly shows that from a certain temperature the nature of the oil evolves. This confirms the results of our previous studies which showed that, starting from a certain temperature depending on the oil, the nature of the latter evolved following the thermal decomposition of the triglycerides it contains.

For each recommended estimation model, the curves of the physical properties as well as the ARDs of the two oils can differ depending on the physical property under consideration. The rapeseed and jatropha oils are substantially different in their fatty acid composition. Indeed, according to the Table 2, although both oils are mono-unsaturated, rapeseed oil contains more than $8 \%$ of linolenic acid while jatropha oil does not contain any. This difference in terms of fatty acid composition certainly affects the physical properties of vegetable oils as well as their evolution with temperature. This is in accordance with literature results [49].

\section{Conclusions}

This work gives tools to overcome the difficulty to determine experimentally physical properties for vegetable oils within the range of temperature typically observed during the injection phase in diesel engine. Based on experimental physical properties of pure vegetable oils determined in this study and existing theoretical models, this work has shown that, within the range 298 to $523 \mathrm{~K}$, rapeseed and jatropha oils' physical properties can be satisfactorily predicted as a function of temperature using group-contribution approach. In this temperature range, it was found that for the prediction of oil density, the Gunn Yamada method was the most accurate, and in line with our experimental data, with an ARD of 1.34 for Rapeseed oil and 0.04 for Jatropha oil. Dynamic viscosity was found to be well-predicted by the Jöback-Lyderson method above $350 \mathrm{~K}$. The calculated ARD of 28.39 for Rapeseed oil and 20.42 for Jatropha oil is much higher because of the large deviation observed at lower temperatures. Thermal conductivity and Heat Capacity were respectively found to be well predicted by 
Sastri and Zong et al. methods with ARD lower than 7.75 for both Rapeseed and Jatropha oils.

Further studies to be conducted on vegetable oils having extreme fatty acid composition will allow correlating more specifically the evolution up to $523 \mathrm{~K}$ of a given physical property to the composition of oils.

\section{Acknowledgements}

A.S. Zongo expresses his gratitude to French Cooperation in Burkina Faso who, through the Service for Cooperation and Cultural Action (SCAC), financed this study by awarding an internship fellowship in 2017 at CIRAD Montpellier.

\section{Conflicts of Interest}

The authors declare no conflicts of interest regarding the publication of this paper.

\section{References}

[1] Ramadhas, A.S., Jayara, J.S. and Muraleedharan, C. (2004) Use of Vegetable Oils as I.C. Engine Fuels-A Review. Renewable Energy, 29, 727-742. https://doi.org/10.1016/j.renene.2003.09.008

[2] Misra, R.D. and Murthy, M.S. (2010) Straight Vegetable Oils Usage in a Compression Ignition Engine. Renewable and Sustainable Energy Reviews, 14, 3005-3013. https://doi.org/10.1016/j.rser.2010.06.010

[3] Altin, R., Cetinkaya, S. and Yücesu, H.S. (2001) The Potential of Using Vegetable Oil Fuels as Fuel for Diesel Engines. Energy Conversion and Management, 42, 529-538. https://doi.org/10.1016/S0196-8904(00)00080-7

[4] Peterson, C.L., Wagner, G.L. and Auld, D.L. (1983) Vegetable Oil Substitutes for Diesel Fuels. Transactions of the American Society of Agricultural Engineers, 26, 0322-0327. https://doi.org/10.13031/2013.33929

[5] José, J.S., Sanz-Tejedor, M.A. and Arroyo, Y. (2015) Effect of Fatty Acid Composition in Vegetable Oils on Combustion Processes in an Emulsion Burner. Fuel Processing Technology, 130, 20-30. https://doi.org/10.1016/j.fuproc.2014.09.036

[6] Agarwal, D. and Agarwal, A.K. (2007) Performance and Emissions Characteristics of Jatropha Oil (Preheated and Blends) in a Direct Injection Compression Ignition Engine. Applied Thermal Engineering, 27, 2314-2323. https://doi.org/10.1016/j.applthermaleng.2007.01.009

[7] Devan, P.K. and Mahalakshmi, N.V. (2009) A Study of the Performance, Emission and Combustion Characteristics of a Compression Ignition Engine Using Methyl Ester of Paradise Oil-Eucalyptus Oil Blends. Applied Energy, 86, 675-680. https://doi.org/10.1016/j.apenergy.2008.07.008

[8] Prasad, C.M.V., Krishna, M.V.S., Reddy, C.P. and Mohan, K.R. (2000) Performance Evaluation of Non-Edible Vegetable Oils as Subtitute Fuels in Low Heat Rejection Diesel Engines. Proceedings of the Institution of Mechanical Engineers, Part D: Journal of Automobile Engineering, 214, 181-188. https://doi.org/10.1177/095440700021400207

[9] Labeckas, G. and Slavinskas, S. (2003) The Analysis of Diesel Engine Performance on Pure Rapeseed Oil. Proceedings of 4th International Conference, Vilnius Gediminas Technical University, Techika, Vilnius, 490-496. 
[10] Zongo, A.S. (2015) Etude des processus physiques et chimiques mis en jeu lors de la combustion des huiles végétales pures dans les moteurs diesel: mécanismes de décomposition et de polymérisation. Ph D, Ouaga I Pr Joseph KI-ZERBO/Université d'Orléans.

[11] Agarwal, D., Lokesh, K. and Agarwal, A.K. (2008) Performance Evaluation of a Vegetable Oil Fuelled Compression Ignition Engine. Renewable Energy, 33, 1147-1156. https://doi.org/10.1016/j.renene.2007.06.017

[12] Daho, T., Vaïtilingom, G., Sanogo, O., Ouiminga, S.K., Segda, B.G., Valette, J., Higelin, P. and Koulidiati, J. (2012) Study of Droplet Vaporization of Various Vegetable Oils and Blends of Domestic Fuel Oil-Cottonseed Oil under Different Ambient Temperature Conditions. Biomass and Bioenergy, 46, 653-663.

https://doi.org/10.1016/j.biombioe.2012.06.031

[13] Daho, T., Vaïtilingom, G., Sanogo, O., Ouiminga, S.K., Segda, B.G., Valette, J., Higelin, P. and Koulidiati, J. (2012) Model for Predicting Evaporation Characteristics of Vegetable Oils Droplets Based on Their Fatty Acid Composition. International Journal of Heat and Mass Transfer, 55, 2864-2871. https://doi.org/10.1016/j.ijheatmasstransfer.2012.01.048

[14] Wallek, T., Rarey, J., Metzger, J.O. and Gmehling, J. (2013) Estimation of Pure-Component Properties of Biodiesel-Related Components: Fatty Acid Methyl Esters, Fatty Acids, and Triglycerides. Industrial \& Engineering Chemistry Research, 52, 16966-16978. https://doi.org/10.1021/ie402591g

[15] Ceriani, R., Gonçalves, C.B. and Coutinho, J.A.P. (2011) Prediction of Viscosities of Fatty Compounds and Biodiesel by Group Contribution. Energy \& Fuels, 25, 3712-3717. https://doi.org/10.1021/ef200669k

[16] Freitas, S.V.D., Pratas, M.J., Ceriani, R., Lima, A.S. and Coutinho, J.A.P. (2011) Evaluation of Predictive Models for the Viscosity of Biodiesel. Energy \& Fuels, 25, 352-358. https://doi.org/10.1021/ef101299d

[17] Machado, F.A.L., Zanelato, E.B., Guimarães, A.O., Silva, E.C.D. and Mansanares, A.M. (2012) Thermal Properties of Biodiesel and Their Corresponding Precursor Vegetable Oils Obtained by Photopyroelectric Methodology. International Journal of Thermophysics, 33, 1848-1855. https://doi.org/10.1007/s10765-012-1245-6

[18] Vicente, G., Martínez, M. and Aracil, J. (2006) A Comparative Study of Vegetable Oils for Biodiesel Production in Spain. Energy \& Fuels, 20, 394-398.

https://doi.org/10.1021/ef0502148

[19] Moradi, G.R., Karami, B. and Mohadesi, M. (2013) Densities and Kinematic Viscosities in Biodiesel-Diesel Blends at Various Temperatures. Journal of Chemical \& Engineering Data, 58, 99-105. https://doi.org/10.1021/je3008843

[20] Nogueira, C.A., Carmo, F.R., Santiago, D.F., Nogueira, V.M., Fernandes, F.A.N., Aguiar, R.S.S. and Sant'Ana, H.B.D. (2012) Viscosities and Densities of Ternary Blends of Diesel + Soybean Biodiesel + Soybean Oil. Journal of Chemical \& Engineering Data, 57, 3233-3241. https://doi.org/10.1021/je300838n

[21] Barabás, I. and Todorut, I.A. (2011) Predicting the Temperature Dependent Viscosity of Biodiesel-Diesel-Bioethanol Blends. Energy \& Fuels, 25, 5767-5774. https://doi.org/10.1021/ef2007936

[22] Feitosa, F.X., Rodrigues, M.D.L., Veloso, C.B., Cavalcante, C.L., Albuquerque, M.C.G. and Sant'Ana, H.B.D. (2010) Viscosities and Densities of Binary Mixtures of Coconut + Colza and Coconut + Soybean Biodiesel at Various Temperatures. Journal of Chemical \& Engineering Data, 55, 3909-3914.

https://doi.org/10.1021/je901060j 
[23] Dias, J.M., Alvim-Ferraz, M.C.M. and Almeida, M.F. (2008) Mixtures of Vegetable Oils and Animal Fat for Biodiesel Production: Influence on Product Composition and Quality. Energy Fuels, 22, 3889-3893. https://doi.org/10.1021/ef8005383

[24] Anand, K., Ranjan, A. and Mehta, P.S. (2010) Estimating the Viscosity of Vegetable Oil and Biodiesel Fuels. Energy \& Fuels, 664-672. https://doi.org/10.1021/ef900818s

[25] Anand, K., Ranjan, A. and Mehta, P.S. (2010) Predicting the Density of Straight and Processed Vegetable Oils from Fatty Acid Composition. Energy \& Fuels, 24, 3262-3266. https://doi.org/10.1021/ef100143f

[26] Cunico, L.P., Ceriani, R. and Guirardello, R. (2013) Estimation of Physical Properties of Vegetable Oils and Biodiesel Using Group Contribution Methods. Chemical Engineering Transactions, 32, 535-540.

[27] Wang, C. and Erhan, S. (1999) Studies of Thermal Polymerization of Vegetable Oils with a Differential Scanning Calorimeter. JAOCS, 76, 1211-1216. https://doi.org/10.1007/s11746-999-0096-1

[28] Wilson, L.C., Wilson, H.L., Wilding, W.V. and Wilson, G.M. (1996) Critical Point Measurements for Fourteen Compounds by a Static Method and a Flow Method. Journal of Chemical \& Engineering Data, 41, 1252-1254. https://doi.org/10.1021/je960052x

[29] VonNiederhausern, D.M., Wilson, G.M. and Giles, N.F. (2006) Critical Point and Vapor Pressure Measurements for Four Compounds by a Low Residence Time Flow Method. Journal of Chemical \& Engineering Data, 51, 1986-1989. https://doi.org/10.1021/je0602465

[30] Nikitin, E.D., Pavlov, P.A. and Skripov, P.V. (1993) Measurement of the Critical Properties of Thermally Unstable Substances and Mixtures by the Pulse-Heating Method. The Journal of Chemical Thermodynamics, 25, 869-880. https://doi.org/10.1006/jcht.1993.1084

[31] Plank, M., Wachtmeister, G., Remmele, E., Thuneke, K. and Emberger, P. (2017) Ignition Characteristics of Straight Vegetable Oils in Relation to Combustion and Injection Parameters, as Well as Their Fatty Acid Composition. Fuel Processing Technology, 167, 271-280. https://doi.org/10.1016/j.fuproc.2017.07.007

[32] Mehta, P.S. and Anand, K. (2009) Estimation of a Lower Heating Value of Vegetable Oil and Biodiesel Fuel. Energy \& Fuels, 23, 3893-3898. https://doi.org/10.1021/ef900196r

[33] Mishra, S., Anand, K. and Mehta, P.S. (2016) Predicting the Cetane Number of Biodiesel Fuels from Their Fatty Acid Methyl Ester Composition. Energy \& Fuels, 30, 10425-10434. https://doi.org/10.1021/acs.energyfuels.6b01343

[34] Hoffmann, J.-F., Henry, J.-F., Vaitilingom, G., Olives, R., Chirtoc, M., Caron, D. and Py, X. (2016) Temperature Dependence of Thermal Conductivity of Vegetable Oils for Use in Concentrated Solar Power Plants, Measured by 3omega Hot Wire Method. International Journal of Thermal Sciences, 107, 105-110. https://doi.org/10.1016/j.ijthermalsci.2016.04.002

[35] Neto, E.G.L., Silva, G.P. and Silva, G.F. (2012) Evaluation of Group-Contribution Methods to Estimate Vegetable Oils and Biodiesel Properties. International Journal of Engineering and Technology, 2, 1600-1605.

[36] Marrero, J. and Gani, R. (2001) Group-Contribution Based Estimation of Pure Component Properties. Fluid Phase Equilibria, 183-208. https://doi.org/10.1016/S0378-3812(01)00431-9

[37] Jain, A., Yang, G. and Yalkowsky, S.H. (2004) Estimation of Melting Points of Or- 
ganic Compounds. Industrial \& Engineering Chemistry Research, 43, 7618-7621. https://doi.org/10.1021/ie049378m

[38] Su, Y.C. (2011) Selection of Prediction Methods for Thermophysical Properties for Process Modeling and Product Design of Biodiesel Manufacturing. Virginia Polytechnic Institute and State University.

[39] Poling, B.E., Prausnitz, J.M. and O'connel, J.P. (2001) The Properties of Gases and Liquids. 8th Edition, McGraw-Hill, New York.

[40] Morad, N.A., Kamal, A.A.M., Panau, F. and Yew, T.W. (2000) Liquid Specific Heat Capacity Estimation for Fatty Acids, Triacylglycerols, and Vegetable Oils Based on Their Fatty Acid Composition. JAOCS, 77, 1001-1005. https://doi.org/10.1007/s11746-000-0158-6

[41] Morris, P.S. (1964) M.S Thesis. Polytechnic Institute of Brooklyn, New York.

[42] Technology, D. (1995) Predict Chemical Thermodynamic \& Transport Properties of Interest to Chemical Engineers and Chemists, Version 4.

[43] Zong, L., Ramanathan, S. and Chen, C.C. (2010) Fragment-Based Approach for Estimating Thermophysical Properties of Fats and Vegetable Oils for Modeling Biodiesel Production Process. Industrial \& Engineering Chemistry Research, 49, 876-886. https://doi.org/10.1021/ie900513k

[44] Ceriani, R., Gani, R. and Meirelles, A.J.A. (2009) Prediction of Heat Capacities and Heats of Vaporization of Organic Liquids by Group Contribution Methods. Fluid Phase Equilibria, 283, 49-55. https://doi.org/10.1016/j.fluid.2009.05.016

[45] Lima Neto, E.G., Silva, G.P. and Silva, G.F. (2012) Evaluation of Group Contribution Methods to Estimate Vegetable Oils and Biodiesel Properties. International Journal of Engineering and Technology, 9, 1600-1605.

[46] Santos, J.C.O., Santos, I.M.G. and Souza, A.G. (2005) Effect of Heating and Cooling on Rheological Parameters of Edible Vegetable Oils. Journal of Food Engineering, 67, 401-405. https://doi.org/10.1016/j.jfoodeng.2004.05.007

[47] Balderas Lopez, J.A., Galvez Coyt, G., Munoz Diosdado, A. and Diaz Reyes, J. (2013) Thermal Characterization of Vegetable Oils by Means of Photoacoustic Techniques. Revista Mexicana de Fisica, 59, 168-172.

[48] Brock, J., Nogueira, M.R., Zakrzevski, C., Corazza, F.D.C., Corazza, M.L. and De Oliveira, J.V. (2008) Experimental Measurements of Viscosity and Thermal Conductivity of Vegetable Oils. Ciência e Tecnologia Alimentos, 28, 564-570. https://doi.org/10.1590/S0101-20612008000300010

[49] Sanz-Tejedor, M., Ascensión, Y.A. and José, J.S. (2016) Influence of Degree of Unsaturation on Combustion Efficiency and Flue Gas Emissions of Burning Five Refined Vegetable Oils in an Emulsion Burner. Energy \& Fuels, 30, 7357-7366. https://doi.org/10.1021/acs.energyfuels.6b01183 


\section{Nomenclature}

\begin{tabular}{|c|c|c|c|}
\hline ARD & : Average relative deviation, $\%$ & $T_{\text {ref }}$ & : Reference temperature, $\mathrm{K}$ \\
\hline$C_{l p}$ & : Liquid phase specific heat & $V_{c}$ & : Critic volume, $\mathrm{cm}^{3} / \mathrm{mol}$ \\
\hline$C_{p}$ & : Heat capacity & $W$ & : Acentric factor \\
\hline$C_{p}^{\circ}$ & : Ideal gas heat capacity, $\mathrm{kj} / \mathrm{kmol} \mathrm{K}$ & $x_{i}$ & : Mole fraction of component $i$ \\
\hline$E_{V}$ & : Estimated value & $Z_{R A i}$ & : Rackett parameter of component $i$ \\
\hline$F_{c}$ & : Correction factor & $\Delta \lambda_{b}$ & : Thermal conductivity group contribution \\
\hline$L_{V}$ & : Litterature value & $\Delta \lambda_{\text {cor }}$ & : Thermal conductivity correction factor \\
\hline$M_{W}$ & : Molecular weight & $\Delta \mu_{a}$ & : Jöback groups' contributions a \\
\hline$M_{W i}$ & : Molecular weight of component i & $\Delta \mu_{b}$ & : Jöback groups' contributions $b$ \\
\hline$N$ & : Number of data points & $\Delta \mu_{M}$ & : Group contributions factors \\
\hline$T_{b r}$ & : Quotient of the boiling temperature, $\mathrm{K}$ & $\lambda_{0}$ & : Reference thermal conductivity \\
\hline$N_{\text {frag }}$ & : Fragment number & $\lambda_{L}$ & : Liquid thermal conductivity \\
\hline$N_{k}$ & : Number of group $k$ & $\mu^{+}$ & : Compound class group contribution \\
\hline$P_{c i}$ & : Critical pression of component $i$ & $\mu_{L}$ & : Liquid dynamic viscosity \\
\hline$R$ & : Universal gas constant & $\rho_{\text {oil }}$ & : Density of vegetable oil \\
\hline$T_{R}$ & : Reduced temperature, $\mathrm{K}$ & $\rho_{\text {ref }}$ & : Density at reference temperature \\
\hline
\end{tabular}

